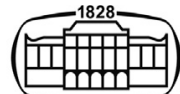

AKADÉMIAI KIADÓ

Acta Veterinaria

Hungarica

$68(2020) 2,186-192$

DOI:

$10.1556 / 004.2020 .00030$

(C) 2020 Akadémiai Kiadó

\section{ORIGINAL ARTICLE}

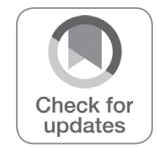

*Corresponding author.

E-mail: Igor.Ujcic.Vrhovnik@vf.uni-lj.si Tel.:+38614779232

\title{
The effects of feed naturally contaminated with Fusarium mycotoxins on the thymus in suckling piglets
}

\author{
IGOR UJČIČ-VRHOVNIK ${ }^{1 *} \odot$, TANJA ŠVARA ${ }^{2}$, \\ TADEJ MALOVRH ${ }^{3}$ and BREDA JAKOVAC-STRAJN ${ }^{1}$
}

\author{
${ }^{1}$ Institute of Food Safety, Feed and Environment, Veterinary Faculty, University of Ljubljana, \\ Gerbičeva 60, 1115, Ljubljana, Slovenia \\ ${ }^{2}$ Institute of Pathology, Wild Animals, Fish and Bees, Veterinary Faculty, University of Ljubljana, \\ Ljubljana, Slovenia \\ ${ }^{3}$ Institute of Microbiology and Parasitology, Veterinary Faculty, University of Ljubljana, Ljubljana, \\ Slovenia
}

Received: October 25, 2019 • Accepted: March 09, 2020

Published online: August 31, 2020

\begin{abstract}
In this study, feed naturally containing Fusarium mycotoxins was fed to gilts during the perinatal period, and the effects on the thymus were investigated in one-week-old piglets. Twenty gilts were divided into equal control (0.26 mg deoxynivalenol, DON) and experimental (5.08 mg DON, $0.09 \mathrm{mg}$ zearalenone and $21.61 \mathrm{mg}$ fusaric acid per $\mathrm{kg}$ of feed) groups. One suckling piglet from each litter ( $n$ $=20$ ) was sacrificed at one week of age to obtain thymus samples for further analysis. The cortex to medulla ratio of the thymus was morphometrically analysed using NIS Elements BR (Nikon) software. Paraffin-embedded thymus sections were stained to quantify apoptosis (with terminal deoxynucleotidyl transferase-mediated dUTP nick-end labelling - TUNEL method), cellular proliferation (Ki-67) and macrophages (MAC 387). The results showed that the thymus cortex $(P=0.023)$ to medulla $(P=0.023)$ ratio was significantly lower in the experimental group. The number of apoptotic cells (cortex, $P=0.010$, medulla, $P=0.001$ ) and the number of proliferating cells in the thymus cortex $(P=0.001)$ and medulla $(P<0.001)$ were significantly higher in the experimental group. Our results indicate that feeding Fusarium mycotoxins to a parent animal during the perinatal period induces significant alterations in the thymus of one-week-old piglets, which indicates an immunosuppressive effect in piglets.
\end{abstract}

\section{KEYWORDS}

Fusarium mycotoxins, piglets, thymus

\section{INTRODUCTION}

In recent years, cereals (wheat, barley, maize) have most commonly been contaminated with moulds of the genus Fusarium, producing an extremely important group of mycotoxins called trichothecenes. The trichothecenes are divided into four groups based on their characteristic functional groups (Biro, 2003). Deoxynivalenol (DON) is a mycotoxin classified as a type B trichothecene. Recent surveys have indicated that more than $50 \%$ of different cereal samples were positive for DON contamination (Streit et al., 2012; Aiko and Mehta, 2015; Ferrigo et al., 2016; Lee and Ryu, 2017). In addition to its emetic effects, chronic dietary exposure to DON causes impaired weight gain, anorexia, decreased nutritional efficiency and substantial immune dysregulation. The mycotoxin-induced disruption of the intestinal barrier and the subsequent immunomodulation are significant from an animal health and welfare point of view. Among the different species of animals, pigs are the most sensitive to 
DON (Biro, 2003). The susceptibility of pigs to other Fusarium mycotoxins such as zearalenone (ZEN) and fumonisins is also known (Pierron et al., 2016). Moreover, in pigs a synergistic interaction between DON and fusaric acid (FA) has also been reported (Smith et al., 1997).

Few reports have been published on the effects of feeding grains naturally contaminated with DON to sows and the subsequent adverse alterations in piglets (Jakovac-Strajn et al., 2009; Malovrh and Jakovac-Strajn, 2010), despite the evidence that DON can pass through the porcine placental barrier (Dänicke et al., 2007; Goyarts et al., 2010). Changes in thymus histopathology and architecture are considered particularly relevant when screening for immunotoxicity (Elmore, 2006). Hence, in addition to clinical observations regarding parturition and the measurement of immunoglobulin concentrations in the colostrum and the blood serum of piglets as published in a previous report (JakovacStrajn et al., 2009), in this paper we report specific alterations within the thymus of the one-week-old piglets examined. In particular, we evaluated thymus architecture by quantifying the cortex to medulla ratio and the number of apoptotic cells, macrophages and proliferating cells.

\section{MATERIALS AND METHODS}

\section{Experimental animals and diets}

This study forms part of an experiment previously reported by Jakovac-Strajn et al. (2009). Briefly, 20 gilts that were approximately 315 days old (body weight: $191.7 \pm 12.3 \mathrm{~kg}$ ) were chosen at random from 29 Landrace $\times$ Large White gilts inseminated on the same farm in the same week. At the start of the experiment, the gilts were at $89 \pm 2$ days of gestation.

The gilts were divided into two equal groups: a control and an experimental group ( $n=10$ gilts/group). Chemical analysis of the diet fed to the experimental group revealed a concentration of $5.08 \mathrm{mg}$ DON, $0.09 \mathrm{mg}$ ZEN and $21.61 \mathrm{mg}$ FA per $\mathrm{kg}$ of feed. The feed in the control group contained $0.26 \mathrm{mg} / \mathrm{kg}$ DON. Both ZEN $(<0.02 \mathrm{mg} / \mathrm{kg})$ and FA $(<0.77$ $\mathrm{mg} / \mathrm{kg}$ ) were below the detection limits. In both feeds, the concentrations of aflatoxin $\mathrm{B}_{1}(<0.2 \mu \mathrm{g} / \mathrm{kg}), 15$ A-DON, nivalenol, fusarenon-X, DAS, T-2 toxin, HT-2 toxin $(<0.05$ $\mu \mathrm{g} / \mathrm{kg})$, ochratoxin $\mathrm{A}$ and fumonisins $\mathrm{B}_{1}, \mathrm{~B}_{2}$ and $\mathrm{B}_{3}(<10 \mu \mathrm{g} /$ $\mathrm{kg}$ ) were also below the detection limits of high-performance liquid chromatography (HPLC).

Composition and nutritional value were the same for both diets and met all nutritional requirements for gestating and lactating sows (NRC, 1998). During gestation, the sows were fed $3.5 \mathrm{~kg}$ /day of diet divided into two meals (6 a.m. and 1 p.m.). The feed allowance provided from the day of farrowing until weaning (at 21 days old) was $6.0 \mathrm{~kg}$ per sow per day. Deliveries in both groups started 24-27 days after the start of the feeding experiment.

One suckling piglet from each litter (a total of 20 piglets) were sacrificed using the euthanasia agent T61 (embutramide/mebezonium iodide/tetracaine hydrochloride,
Intervet Deutschland GmbH, Unterschleissheim, Germany) when the piglets were one week old.

These experiments were carried out with the approval of the Veterinary Administration of the Republic of Slovenia.

\section{Sample collection}

Immediately after euthanasia, thymus samples were obtained, fixed in 10\% phosphate-buffered formalin and embedded in paraffin using a routine protocol.

\section{Determination of the cortex to medulla ratio of the thymus}

Sections ( $4 \mu \mathrm{m}$ thick) were stained with haematoxylin and eosin (HE). The cortex to medulla ratio of the thymus was analysed morphometrically using a digital camera (DS-U2, Nikon) connected to a microscope (Microphot FXA, Nikon) and NIS Elements BR (Nikon) software. Twenty random fields in each sample were photographed at $\times 40$ magnification. The cortex and medulla of the thymus were outlined in the micrographs, and the relative ratio of the cortex and medulla was calculated.

\section{Apoptosis in the thymic cortex and medulla}

To quantify cellular apoptosis, terminal deoxynucleotidyl transferase-mediated dUTP nick-end labelling (TUNEL) was performed on 4 - $\mu$ m-thick paraffin-embedded sections. A commercially available ApopTag ${ }^{\circledR}$ Peroxidase In Situ Apoptosis Detection Kit (Chemicon) was used according to the manufacturer's instructions. The TUNEL-positive cells in the thymic cortex and medulla were counted in five random fields per sample at $\times 400$ magnification. The apoptotic index was expressed as the average number of TUNEL-positive cells per field.

\section{Cellular proliferation index and number of macrophages}

To determine cell proliferation and to count macrophages, 4 - $\mu \mathrm{m}$-thick paraffin-embedded sections were deparaffinised and antigen demasking was performed by boiling the tissue slices in EDTA buffer ( $\mathrm{pH}$ 9.0) in a microwave oven for 10$15 \mathrm{~min}$. Thereafter the slides were incubated with a monoclonal mouse anti-human antibody against Ki-67 [antigen clone MIB-1 (DAKO), diluted 1:75] for $1 \mathrm{~h}$ at room temperature in a humid chamber. Then, endogenous peroxidase activity was quenched with Peroxidase-Blocking Solution (Dako REAL ${ }^{\mathrm{TM}}$, DAKO) for $30 \mathrm{~min}$ at room temperature. Subsequently, a kit [DAKO REAL ${ }^{\mathrm{TM}}$ EnVision $^{\mathrm{TM}}$ Detection System Peroxidase/DAB+, Rabbit/Mouse (DAKO)] was used to visualise the immunolabelling. The sections were then counterstained with HE and mounted. The proliferation index was determined by counting the number of $\mathrm{Ki}$ 67-positive cells per 1,000 cells in five randomly selected fields at $\times 400$ magnification and expressed in the table as the number of Ki-67-positive cells per 1,000 counted cells. The proliferation index was determined separately for both the thymic cortex and medulla. 
The macrophages were counted after labelling the cells with a monoclonal mouse anti-human antibody against MAC 387 (DAKO, diluted 1:100), separately in the thymic cortex and medulla in five randomly selected fields per sample at $\times 400$ magnification.

\section{Statistical analysis}

The data obtained in this study were statistically analysed, and the significances of differences between groups were determined using a non-parametric Mann-Whitney U test. A difference was considered significant when $P<0.05$. Pearson's correlation was used to identify correlations between continuous variables. All calculations were performed in the statistical program SPSS (Statistical Package for Social Sciences, Version 12, November 2003).

\section{RESULTS}

As described previously (Jakovac-Strajn et al., 2009), the gilts in the experimental group consumed significantly less feed than those in the control group. From the beginning of the experiment to delivery, the daily feed consumption was 2.9 $\pm 0.3 \mathrm{~kg}$ in the experimental group and $3.4 \pm 01 \mathrm{~kg}$ in the control group $(P=0.02)$. During lactation, the feed consumption of the experimental group and the control group was $4.1 \pm 0.6 \mathrm{~kg}$ and $4.7 \pm 0.5 \mathrm{~kg}$, respectively $(P=0.027)$, while from weaning to insemination the feed intake was 2.6 $\pm 0.4 \mathrm{~kg}$ in the experimental group and $3.4 \pm 0.2 \mathrm{~kg}$ in the control group $(P<0.001)$.
The results of histological and immunohistological analysis of the thymus are shown in Table 1.

\section{Cortex to medulla ratio of the thymus}

There was a significant difference in thymic cortex to medulla ratio between the experimental and the control group $(P=0.023)$. The area of the thymic medulla was significantly greater in the experimental group than in the control group $(P=0.023)$ (Table 1$)$. There was no correlation between feed consumption and the results obtained in the cortex $(R=0.008, P=0.983)$ and medulla $(R=-0.008, P$ $=0.983)$.

\section{Apoptosis in the cortex and medulla of the thymus}

TUNEL labelling revealed apoptotic cells in the thymus of all piglets. However, the average number of apoptotic cells was significantly higher in the piglets of the experimental group than in those of the control group (thymic cortex, $P=0.010$; thymic medulla, $P=0.001$ ). Additionally, we demonstrated that the rate of apoptosis was higher in both the cortex and the medulla of the thymus (Table 1, Fig. 1) of the toxin-fed animals. The amount of feed consumed did not affect the number of apoptotic cells in the thymic cortex $(R=0.343, P$ $=0.366)$ and medulla $(R=0.089, P=0.821)$.

\section{Cell proliferation}

In the thymic cortex of piglets of the experimental group, the proliferation index was $43.60 \%$, while in the control group it was $32.35 \%$, and this difference was statistically significant

Table 1. Results of histological and immunohistological analysis of the thymus in one-week-old piglets delivered by gilts in the control (0.26 $\mathrm{mg} / \mathrm{kg} \mathrm{DON}$ ) and experimental (5.08 mg DON, $0.09 \mathrm{mg}$ ZEN and $21.61 \mathrm{mg} / \mathrm{kg} \mathrm{FA}$ ) groups

\begin{tabular}{|c|c|c|c|c|c|c|c|c|}
\hline \multirow[b]{4}{*}{ Number of samples } & \multicolumn{8}{|c|}{ Group } \\
\hline & \multicolumn{3}{|c|}{ Control } & \multicolumn{3}{|c|}{ Experimental } & \multirow[b]{3}{*}{ Mann-Whitney U } & \multirow[b]{3}{*}{$P$} \\
\hline & \multicolumn{3}{|c|}{10} & \multicolumn{3}{|c|}{10} & & \\
\hline & Median & Min & Max & Median & Min & $\operatorname{Max}$ & & \\
\hline \multicolumn{9}{|l|}{ Area percentage ratio $^{a}$} \\
\hline thymus cortex & 77.00 & 71.41 & 83.14 & 71.93 & 63.89 & 83.21 & 20.00 & 0.023 \\
\hline thymus medulla & 23.00 & 16.86 & 28.59 & 28.07 & 16.79 & 36.11 & 20.00 & 0.023 \\
\hline \multicolumn{9}{|l|}{ Apoptosis ${ }^{\mathrm{b}}$} \\
\hline thymus cortex & 7.70 & 5.60 & 15.40 & 11.50 & 8.80 & 15.20 & 16.00 & 0.010 \\
\hline thymus medulla & 3.10 & 1.60 & 6.60 & 7.60 & 5.80 & 9.20 & 6.50 & 0.001 \\
\hline \multicolumn{9}{|l|}{ Proliferation index ${ }^{c}$} \\
\hline thymus cortex & 323.50 & 243.00 & 378.00 & 436.00 & 319.00 & 577.00 & 5.00 & 0.001 \\
\hline thymus medulla & 115.50 & 95.00 & 152.00 & 211.50 & 185.00 & 388.00 & 0.00 & $<0.001$ \\
\hline \multicolumn{9}{|l|}{ Macrophages $^{\mathrm{d}}$} \\
\hline thymus cortex & 18.20 & 12.80 & 27.00 & 23.90 & 11.40 & 35.20 & 29.00 & 0.112 \\
\hline thymus medulla & 10.30 & 7.80 & 13.80 & 9.80 & 6.40 & 12.40 & 43.00 & 0.596 \\
\hline
\end{tabular}

$\mathrm{DON}=$ deoxynivalenol, $\mathrm{ZEN}=$ zearalenone, $\mathrm{FA}=$ fusaric acid.

${ }^{a}$ Percentage ratio (\%) of the thymus cortex and medulla (determined by counting in 20 visual fields at $\times 40$ magnification) in the control and experimental groups.

${ }^{\mathrm{b}}$ The average number of TUNEL-positive cells in the thymus cortex and medulla (counted in 5 visual fields at $\times 400$ magnification) in the control and experimental groups.

${ }^{\mathrm{c}}$ The proliferation index was determined by counting the number of Ki-67-positive cells per 1,000 cells in 5 randomly selected visual fields at $\times 400$ magnification in the control and experimental groups.

${ }^{\mathrm{d}}$ The average number of macrophages (counted in 5 visual fields at $\times 400$ magnification) in the control and experimental groups. 

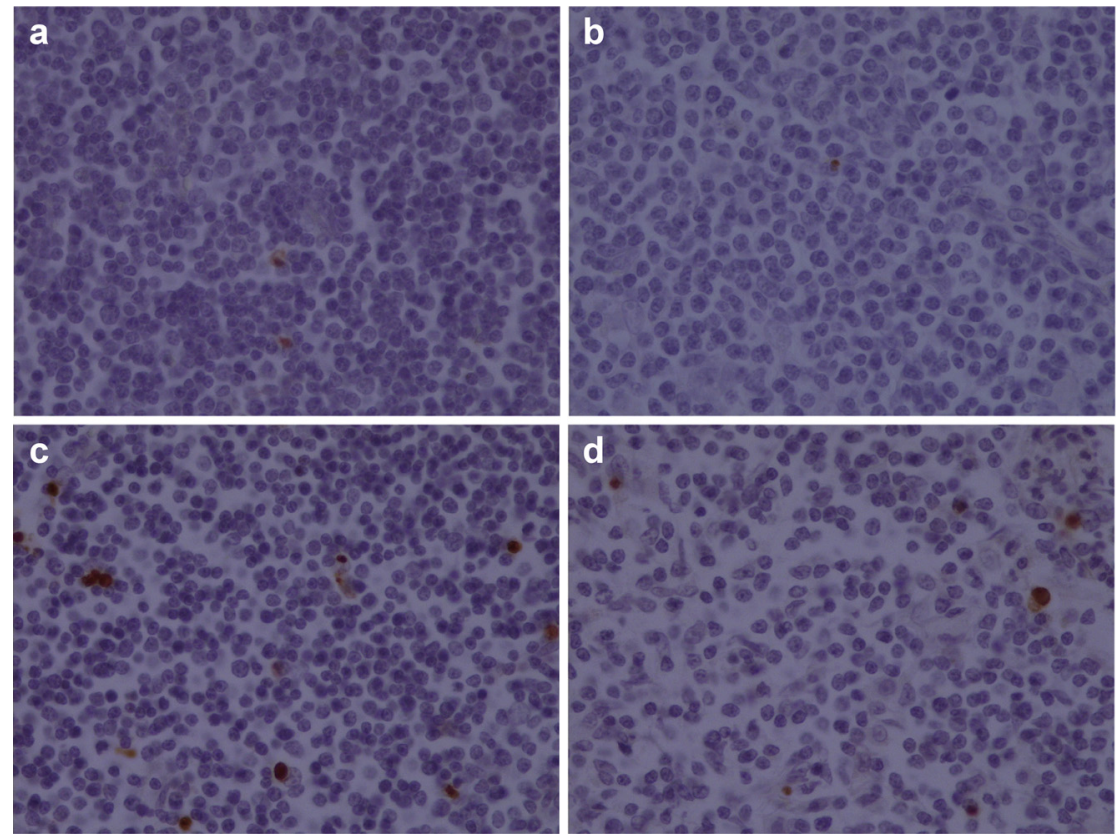

Fig. 1. a and b. Single TUNEL-positive cells were observed in the thymus cortex and medulla in the control group. $c$ and d. Numerous

TUNEL-positive cells were observed in the thymus cortex and medulla in the experimental group. The slides were stained using an ApopTag $^{\circledR}$ kit (Chemicon) and counterstained with haematoxylin (magnification: $\times 400$ )

$(P=0.001)$. In the thymic medulla, the cell proliferation index was $21.15 \%$ in the experimental group and $11.55 \%$ in the control group (Table 1, Fig. 2). There was no correlation between feed consumption and the results obtained in the thymic cortex $(R=-0.142, P=0.715)$ and medulla $(R=$ $0.034, P=0.932)$.

\section{Number of macrophages}

The average number of macrophages in the thymic cortex and medulla was similar in both groups, and a statistical analysis revealed no significant differences (thymic cortex, $P$ $=0.112$; thymic medulla, $P=0.596$ ) (Table 1 ). There was
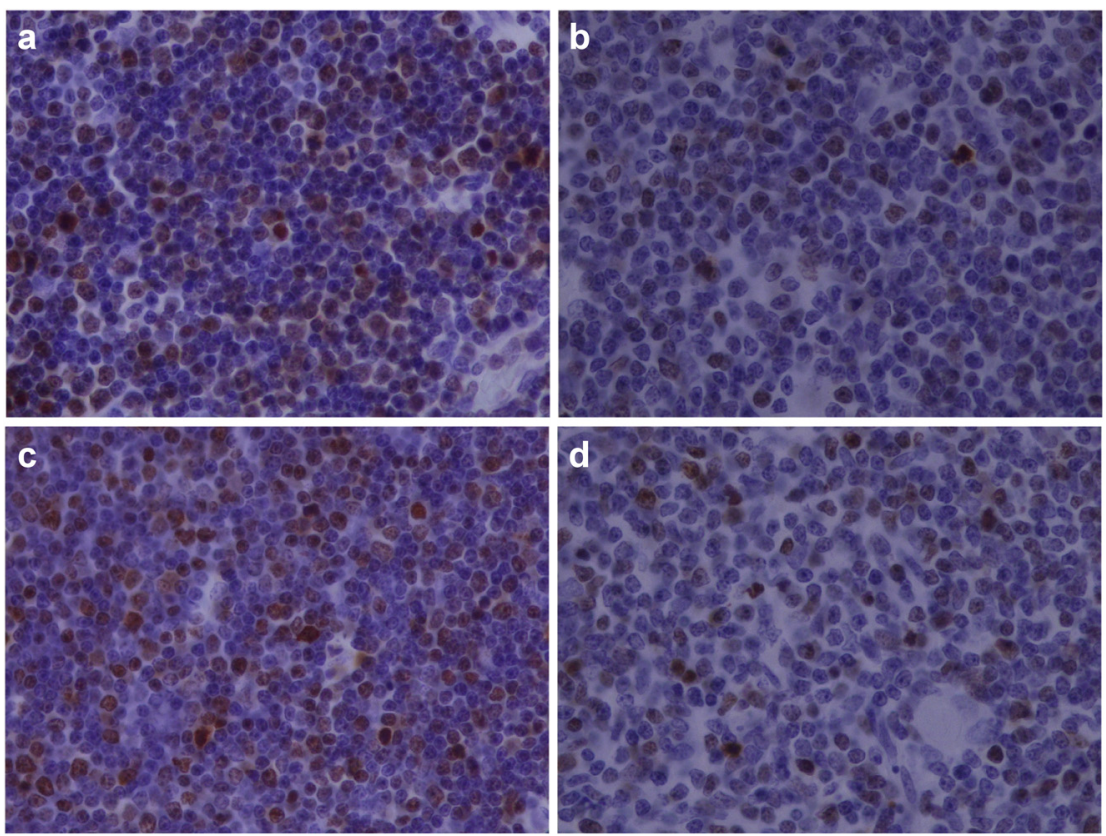

Fig. 2. Immunohistochemical staining performed using an antibody for Ki-67 (antigen clone MIB-1, DAKO). a and b. Proliferating cells in the thymus cortex and medulla of the control group. $\mathrm{c}$ and $\mathrm{d}$. The proliferation index of the thymus cortex and medulla was significantly higher in the experimental group than in the control group. Sections were counterstained with haematoxylin (magnification: $\times 400$ ) 
no correlation between feed consumption and the results obtained in the thymic cortex $(R=0.184, P=0.635)$ and medulla $(R=-0.168, P=0.666)$.

\section{DISCUSSION}

The results obtained in this study indicate that Fusarium mycotoxins, when present in the diet of pregnant and nursing gilts, influence the architecture and cell composition of the thymus of one-week-old piglets.

Lymphocytes (thymocytes) within the cortex of the thymus appear to be especially susceptible to toxic compounds (Elmore, 2006). The numbers of apoptotic and proliferating cells in the thymic cortex and medulla were significantly higher in the experimental group than in the control group. Additionally, when the morphology was examined, a decrease in cellularity was detected in the cortex and, in fewer cases, also in the medulla, or both. This is indicative of immunosuppression (Pearse, 2006b). Apoptotic bodies and macrophages are a normal histological feature of the thymic cortex, particularly in young animals (Pearse, 2006a). However, the loss of cortical lymphocytes through apoptosis is one of the first changes observed in the thymus following a toxic insult. Subsequently, apoptosis is followed by the removal of the apoptotic cellular debris, and this process can lead to the loss of cortico-medullary demarcation and organ atrophy (Pearse, 2006b).

Our results are in accordance with those of previous investigations showing that Fusarium mycotoxins, including DON, induce apoptosis in liver, kidney, gastrointestinal epithelial and immunological cells in addition to several cell lines (Surai and Dvorska, 2005). The results obtained in oneweek-old suckling piglets are of special interest as they indicate that exposure to DON in utero and probable via the colostrum can cause highly significant changes in the architecture and cellularity of the thymus.

As a primary lymphoid organ the thymus is important for primary T cell development (Šinkora and Butler, 2009). In the pig thymus the distribution of lymphocyte subpopulations remained the same from 1 to 40 weeks of age. The percentage of thymocytes detected in one-week-old pigs is highly comparable to that of young adult pigs (Joling et al., 1994). However, information about the ontogeny of the immune system and the development of innate immunity in swine is scarce (Šinkora and Butler, 2009). Early precursor thymocytes, particularly at the double positive CD4+CD8+ stage, are more vulnerable to DON than are very early or late precursor thymocytes. DON induces cellular events that also occur after activation of the $\mathrm{T}$ cell receptor. This $\mathrm{T}$ cell activation in the thymus then evokes negative selection and depletion of thymocytes, which provides a plausible explanation for the high sensitivity of the thymus to DON exposure (Van Kol et al., 2011).

The monoclonal mouse anti-human antibody Ki-67 (antigen clone MIB-1, DAKO) is a common marker of cell proliferation. A significantly higher proliferation rate was observed in the thymus samples in piglets of the experimental group. This might be interpreted as an attempt to compensate for the loss of functional (non-apoptotic) cells.

In previous studies, haematological and clinical-chemical parameters were analysed in fetuses and were not found to be affected when sows were fed a Fusarium toxin-contaminated diet (Goyarts et al., 2007). Using the same animals that were included in the experiments of Goyarts et al. (2007), Tiemann et al. (2008) observed that there were no macroscopic or major histological lesions in the organs of any of the fetuses. They did notice, however, an increase in glycogen content and changes in the architecture of the mitochondria in the livers of fetuses. Goyarts et al. (2010) also detected DON in fetal plasma, and noted that there was variation in the numbers of white blood cells such as lower monocyte and neutrophil counts and higher lymphocyte counts in DON-exposed fetuses. Wippermann et al. (2009) fed sows a mycotoxin-contaminated diet $(4.42 \mathrm{mg} / \mathrm{kg} \mathrm{DON}$, $0.0048 \mathrm{mg} / \mathrm{kg} \mathrm{ZEN}$ ) between days 35 and 70 of gestation and then investigated the effects of DON on immunohistochemical and morphometric parameters of the immune system, liver and intestinal tract of swine fetuses on day 70 of gestation. No alterations were observed that could be associated with DON exposure (Wippermann, 2011). In the present study, similar immunohistochemical methods with similar antibodies were used, but our results showed that DON influenced the architecture and cellularity of the thymus of one-week-old piglets. The main difference between previous works (Goyarts et al., 2007, 2010; Tiemann et al., 2008; Wippermann et al., 2009; Wippermann, 2011) and the current study was the age of the piglets. In our study, the piglets were investigated at the end of their first week of life. Therefore, in addition to intrauterine exposure, these piglets may have also experienced postnatal exposure to DON via the sow's milk, although the excretion of DON in milk had only been detected at trace levels $(<2 \mu \mathrm{g} / \mathrm{kg}$; Friend et al., 1986). Alternatively, thymus maturation might have been too incomplete at 70 days of gestation to show clear alterations following exposure to DON. Indeed, Šinkora et al. (2000) observed transient changes in thymocyte subset composition at 56-74 days of gestation, which can be explained by a gap in pro-T cell delivery to the thymus. This delivery gap is consistent with the expression of the panleukocyte CD45 and pan-myelomonocytic SWC3a markers in fetal liver and bone marrow, and is probably caused by the shifting of primary lymphopoiesis between these organs. Therefore, Sinkora et al. (2000) concluded that the embryonic thymus is colonised by at least two successive waves of haematopoietic progenitors during embryogenesis and that the influx of thymocyte progenitors is discontinuous. Becker and Misfeldt (1993) mentioned that the porcine immune system is not fully developed at birth and the expression of cell surface differentiation antigens seems to occur before the lymphocytes have the ability to respond to mitogens. In oneday-old piglets the thymic parenchyma is not yet well differentiated into a definite cortex and medulla; however, from 5 days of age onwards the thymus of piglets was found 
to consist of an outer cortex and an inner medulla (Sarma et al., 2004). Nevertheless, all primary and secondary lymphoid organs are already present at birth. In neonatal mammals, the period from late gestation to weaning is a critical phase when the adaptive immune system develops and replaces the protection temporarily provided by passive immunity and pre-adaptive antibodies (Butler and Šinkora, 2007).

The findings observed in this study following the intrauterine and galactogenic exposure of one-week-old piglets are in line with those reported by Mikami et al. (2010), in which a histopathological examination of DON-injected pigs (1 $\mathrm{mg} / \mathrm{kg}$ body weight, intravenously) revealed systemic apoptosis in lymphocytes in various lymphoid tissues (e.g. the thymus and the Peyer's patches of the ileum) and hepatocytes. Also, Chen et al. (2008) described a histopathological study and demonstrated that DON and ZEN (1 mg/ $\mathrm{kg}$ and $0.25 \mathrm{mg} / \mathrm{kg}$, respectively) at permitted feed concentrations caused abnormalities in the liver, spleen, lymph nodes, uterus and kidneys. Taken together, these results indicate that quantifiable as well as histomorphological and functional changes can be expected in piglets when sows are exposed to Fusarium mycotoxins.

To exclude the effect of the significantly lower feed consumption of gilts in the experimental group, a correlation analysis of feed intake and the observed alterations was performed. There were no correlations between feed consumption and the results obtained in the cortex and medulla of the thymus.

The alterations observed in the thymus of the piglets described in this study are indicative of changes in the innate immune system. Such alterations could result in an oversensitivity reaction to vaccinations, infections, environmental or dietary antigens (Roth and Thacker, 2006). Previous data have already shown that DON may affect the immune response after vaccination, influence dendritic cells, and decrease the concentrations of serum albumins or globulins (Goyarts et al., 2006; Pinton et al., 2008). In our study, the Fusarium mycotoxin-contaminated feed that was fed to the gilts increased the number of apoptotic cells in the thymic cortex and medulla of one-week-old piglets, whereas the number of proliferating cells in the thymic cortex and medulla was significantly higher in the experimental group than in the control. While these findings suggest that the immune system of the piglets was altered, the clinical relevance of these findings requires further investigation.

Finally it should be mentioned that in practice, the cooccurrence of DON and ZEN and/or additional mycotoxins in contaminated cereals is very common. Also in our study, besides DON and ZEN, the diet contained measurable amounts of FA. In many previous trials with naturally contaminated diets, the concentration of FA was not analysed, even though a synergistic interaction between FA and DON has been reported as FA seems to increase the toxicity of DON in starter pigs (Smith et al., 1997). In contrast, FA was reported to have a low toxicity in the absence of other mycotoxins in the diet (Smith and MacDonald, 1991; Smith and Sousadias, 1993). Whether or not FA can cross the placental barrier remains unknown.

In conclusion, our results provide convincing evidence that intrauterine and galactogenic exposure to diets naturally contaminated with DON and small amounts of ZEN and FA results in measurable alterations in the thymus of one-weekold piglets. This perinatal exposure has often been neglected in previous assessments of the tolerable levels of DON in animal diets, but it warrants further investigation because any impairment of the neonatal immune system could potentially have clinically significant consequences, such as changes in the vulnerability of piglets to infectious diseases and vaccination programs in later stages of life.

\section{ACKNOWLEDGEMENT}

This work was financed with the support of the Slovenian National Research Agency (grant nos. P4-0092).

\section{REFERENCES}

Aiko, V. and Mehta, A. (2015): Occurrence, detection and detoxification of mycotoxins. J. Biosci. 40, 943-954.

Becker, B. A. and Misfeldt, M. L. (1993): Evaluation of the mitogeninduced proliferation and cell surface differentiation antigens of lymphocytes from pigs 1 to 30 days of age. J. Anim. Sci. 71, 2073-2078.

Biro, K. K. (2003): Adverse effects of deoxynivalenol and ochratoxin $\mathrm{A}$ in farm animals: comparative in vivo and in vitro studies. Dissertation, Faculty of Veterinary Medicine, Department of Veterinary Pharmacology, Pharmacy and Toxicology, Utrecht University.

Butler, J. E. and Šinkora, M. (2007): The isolator piglet: a model for studying the development of adaptive immunity. Immunol. Res. 39, 33-51.

Chen, F., Ma, Y., Xue, C., Ma, J., Xie, Q., Wang, G., Bi, Y. and Cao, Y. (2008): The combination of deoxynivalenol and zearalenone at permitted feed concentrations causes serious physiological effects in young pigs. J. Vet. Sci. 9, 39-44.

Dänicke, S., Brüssow, K.-P., Goyarts, T., Valenta, H., Ueberschär, K. H. and Tiemann, U. (2007): On the transfer of the Fusarium toxins deoxynivalenol (DON) and zearalenone ( $\mathrm{ZON})$ from the sow to the full-term piglet during the last third of gestation. Food Chem. Toxicol. 45, 1565-1574.

Elmore, S. A. (2006): Enhanced histopathology of the thymus. Toxicol. Pathol. 34, 656-665.

Ferrigo, D., Raiola, A. and Causin, R. (2016): Fusarium toxins in cereals: occurrence, legislation, factors promoting the appearance and their management. Molecules 21, 627.

Friend, D. W., Trenholm, H. L., Hartin, K. E., Prelusky, D. B. and Thompson, B. K. (1986): Effects of feeding deoxynivalenol (DON)-contaminated wheat diets to pregnant and lactating gilts and on their progeny. Can. J. Anim. Sci. 66, 229-236.

Goyarts, T., Brüssow, K. P., Valenta, H., Tiemann, U., Jäger, K. and Dänicke, S. (2010): On the effects of the Fusarium toxin 
deoxynivalenol (DON) administered per os or intraperitoneal infusion to sows during days 63 to 70 of gestation. Mycotoxin Res. 26, 119-131.

Goyarts, T., Dänicke, S., Brüssow, K.-P., Valenta, H., Ueberschär, K. H. and Tiemann, U. (2007): On the transfer of the Fusarium toxins deoxynivalenol (DON) and zearalenone ( $\mathrm{ZON}$ ) from sows to their fetuses during days 35-70 of gestation. Toxicol. Lett. 171, 38-49.

Goyarts, T., Dänicke, S., Grove, N., Tiemann, U. and Rothkötter, H. J. (2006): Methodical aspects of in vitro proliferation of porcine blood lymphocytes when exposed to deoxynivalenol (DON). Landbauforsch. Völkenrode 56, 139-148.

Jakovac-Strajn, B., Vengušt, A. and Pestevšek, U. (2009): Effects of a deoxynivalenol-contaminated diet on the reproductive performance and immunoglobulin concentrations in pigs. Vet. Rec. 165, 713-718.

Joling, P., Bianchi, A. T., Kappe, A. L. and Zwart, R. J. (1994): Distribution of lymphocyte subpopulations in thymus, spleen, and peripheral blood of specific pathogen free pigs from 1 to 40 weeks of age. Vet. Immunol. Immunopathol. 40, 105-117.

Lee, H. J. and Ryu, D. (2017): Worldwide occurrence of mycotoxins in cereals and cereal-derived food products: public health perspectives of their co-occurrence. J. Agric. Food Chem. 65, 7034-7051.

Malovrh, T. and Jakovac-Strajn, B. (2010): Feed contaminated with Fusarium toxins alter lymphocyte proliferation and apoptosis in primiparous sows during the perinatal period. Food Chem. Toxicol. 48, 2907-2912.

Mikami, O., Yamaguchi, H., Murata, H., Nakajima, Y. and Miyazaki, S. (2010): Induction of apoptotic lesions in liver and lymphoid tissues and modulation of cytokine mRNA expression by acute exposure to deoxynivalenol in piglets. J. Vet. Sci. 11, 107-113.

NRC (National Research Council) (1998): Nutrient Requirements of Domestic Animals. Nutrient Requirements of Swine. 10th revised edition. National Academy Press, Washington, DC. pp. $117-121$.

Pearse, G. (2006a): Normal structure, function and histology of the thymus. Toxicol. Pathol. 34, 504-514.

Pearse, G. (2006b): Histopathology of the thymus. Toxicol. Pathol. 34, 515-547.

Pierron, A., Alassane-Kpembi, I. and Oswald, I. P. (2016): Impact of mycotoxin on immune response and consequences for pig health. Anim. Nutr. 2, 63-68.

Pinton, P., Accensi, F., Beauchamp, E., Cossalter, A. M., Callu, P., Grosjean, F. and Oswald, I. P. (2008): Ingestion of deoxynivalenol (DON) contaminated feed alters the pig vaccinal immune responses. Toxicol. Lett. 177, 215-222.

Roth, J. A. and Thacker, E. L. (2006): Immune system. In: Straw, B. E. and Zimmerman, J. J. (eds) Diseases of Swine. 9th ed. Blackwell Publishing, Ames. pp. 15-31.
Sarma, M., Kalita, S. N. and Sarma, K. (2004): Histology of thymus of indigenous and crossbred piglets during postnatal development. Indian J. Anim. Sci. 74, 1194-1196.

Šinkora, M. and Butler, J. E. (2009): The ontogeny of the porcine immune system. Dev. Comp. Immunol. 33, 237-283.

Šinkora, M., Šinkora, J., Rehakova, Z. and Butler, J. E. (2000): Early ontogeny of thymocytes in pigs: sequential colonization of the thymus by T cell progenitors. J. Immunol. 165, 1832-1839.

Smith, T. K. and MacDonald, E. J. (1991): Effect of fusaric acid on brain regional neurochemistry and vomiting behavior in swine. J. Anim. Sci. 69, 2044-2049.

Smith, T. K., McMillan, E. G. and Castillo, J. B. (1997): Effect of feeding blends of Fusarium mycotoxin-contaminated grains containing deoxynivalenol and fusaric acid on growth and feed consumption of immature swine. J. Anim. Sci. 75, 2184-2191.

Smith, T. K. and Sousadias, M. G. (1993): Fusaric acid content of swine feedstuffs. J. Agric. Food Chem. 41, 2296-2298.

Streit, E., Schatzmayr, G., Tassis, P., Tzika, E., Marin, D., Taranu, I., Tabuc, C., Nicolau, A., Aprodu, I., Puel, O. and Oswald, I. P. (2012): Current situation of mycotoxin contamination and cooccurrence in animal feed - focus on Europe. Toxins 4, 788809.

Surai, P. F. and Dvorska, J. E. (2005): Effects of mycotoxins on antioxidant status and immunity. In: Diaz, D. E. (ed.) The Mycotoxin Blue Book. University Press, Nottingham. pp. 93139.

Tiemann, U., Brüssow, K.-P., Dannenberger, D., Jonas, L., Pöhland, R., Jäger, K., Dänicke, S. and Hagemann, E. (2008): The effect of feeding a diet naturally contaminated with deoxynivalenol (DON) and zearalenone (ZON) on the spleen and liver of sow and fetus from day 35 to 70 of gestation. Toxicol. Lett. 179, 113-117.

Van Kol, S. W. M., Hendriksen, P. J. M., van Loveren, H. and Peijnenburg, A (2011): The effects of deoxynivalenol on gene expression in the murine thymus. Toxicol. Appl. Pharmacol. 250, 299-311.

Wippermann, W. (2011): Diaplazentare Deoxinivalenolintoxikation bei Schweinefeten. Lassen sich am 70. Trachtigkeitstag histomorphologisch und immunhistologisch diagnostisch verwertbare Befunde erheben? Inaugural-dissertation zur Erlangung des grades eines Doctor Medicinae Veterinariae durch die Veterinärmedizinische Fakultät der Universität Leipzig, Leipzig. http://d-nb.info/1020088834/34 (Accessed 30 July 2012).

Wippermann, W., Reischauer, A., Jäger, K., Tiemann, U., Dänicke, S. and Schoon, H. A. (2009): Does the exposure of pregnant sows to deoxynivalenol (DON) affect fetal organs? A pathomorphological and immunohistochemical study. 31st Mycotoxin-Workshop, Münster, Germany, Conference Abstracts, no. 16. 